\title{
Nonproliferatif Diyabetik Retinopati ve Proliferatif Diyabetik Retinopati'de Optik Sinirin Shear-Wave Elastografi ile Değerlendirilmesi ve Santral Retinal Arter Rezistif İndeks Değerleri ile Karşılaştırılması
}

\section{Evaluation of Optic Nerve With Shear-Wave Elastography and Comparing With Central Retinal Artery Resistive Index Values in Nonproliferative Diabetic Retinopathy And Proliferative Diabetic Retinopathy}

\author{
Canan ÇELEBi ${ }^{1}(\mathbb{D})$, Atakan KIRTEKE ${ }^{1} \mathbb{D}$, Abdurrahim DUSAK ${ }^{1}$ (D), \\ Dilek ŞEN DOKUMACI ${ }^{1}$ (D) , Şule ALLAHVERDi ${ }^{1}$
}

${ }^{1}$ Harran Üniversitesi Tıp Fakültesi, Radyoloji Ana bilim Dalı, Şanlıurfa, Türkiye

Öz.

Amaç: Nonproliferatif diyabetik retinopatide ve Proliferatif diyabetik retinopatide optik sinir elastisitesini ve santral retinal arter rezistif indeks değerlerini karşılaştırmayı amaçladık.

Materyal ve Metod: Nonproliferatif diyabetik retinopatili ve Proliferatif diyabetik retinopatili 31 olgunun optik sinir sertlik derecesi Shear-Wave Elastografi tekniğiyle değerlendirildi. Eş zamanlı olarak Renkli Doppler Ultrasonografi yöntemiyle santral retinal arterin rezistif indeks değerleri ölçülerek, kontrol grubuyla karşılaştırıldı.

Bulgular: Retinopatisi olan hastalar, retinopatisi olmayan diyabetik hastalar ve sağlıklı gönüllüler ile karşılaştırıldığında optik sinir Shear-Wave Elastografi değerleri anlamlı olarak yüksek izlendi( $p<0.05)$.

Santral retinal arter rezistif indeks değerleri retinopatisi olan hastalarda olmayanlara göre anlamlı olarak yüksek izlendi $(p<0,05)$. Retinopatisi olmayanlar için Ri değerleri $0,57 \pm 0,88$ ve Retinopatisi olanlarda ise $0,67 \pm 0,53$ olarak ölçüldü.

Sonuç: Diyabetik retinopatinin etyopatogenezi hala tartışmalıdır. Nonproliferatif diyabetik retinopatide ve Proliferatif diyabetik retinopatide Shear-Wave Elastografi ile optik sinirin sertlik derecesinde ve Renkli Doppler Ultrasonografi incelemede oküler kan akım parametrelerinde anlamlı değişiklikler olabilmektedir.

Anahtar Kelimeler: Diyabetik Retinopati, Shear-Wave Elastografi, Optik sinir, Renkli Doppler Ultrasonografi , Santral retinal arter

Abstract

Background: We aimed to compare optic nerve elasticity and central retinal artery resistive index values in Nonproliferative diabetic retinopathy and Proliferative diabetic retinopathy.

Materials and Methods: The degree of optic nerve hardness of 31 patients with nonproliferative diabetic retinopathy and proliferative diabetic retinopathy was evaluated using the Shear-Wave Elastography technique. Simultaneously, the resistive index values of the central retinal artery were measured using Color Doppler Ultrasonography and compared with the control group.

Results: Optic nerve Shear-Wave Elastography values were significantly higher in patients with retinopathy compared to healthy volunteers and diabetic patients without retinopathy $(p<0.05)$.

Central retinal artery resistive index values were significantly higher in patients with retinopathy than those without retinopathy $(p<0.05)$. RI values were measured as $0.57 \pm 0.88$ for those without retinopathy and as $0.67 \pm 0.53$ for those with retinopathy.

Conclusions: The etiopathogenesis diabetic retinopathy is still controversial. Significant changes in the degree of stiffness of the optic nerve and ocular blood flow parameters in Color Doppler Ultrasonography examination can be observed in Nonproliferative diabetic retinopathy and Proliferative diabetic retinopathy with Shear Wave Elastography.

Keywords: Diabetic Retinopathy, Shear-Wave Elastography, Optic nerve, Color Doppler Ultrasonography, Central retinal artery
Sorumlu Yazar / Corresponding Author

Dr. Canan ÇELEBi

Viranşehir Devlet Hastanesi

Yenişehir Mahallesi, Ceylanpınar Cd.

No:3, 63700 Viranşehir/Şanlıurfa

E-mail: canancelik151@gmail.com.tr

Geliş tarihi / Received: 03.03.2021

Kabul tarihi / Accepted: 11.11.2021

DOI: 10.35440/hutfd.889285 


\section{Giriş}

Diyabetes Mellitus(DM) dünyada prevelansı gittikçe artmakta olan sistemik bir hastalıktır. Diyabetik retinopati diyabetin en önemli komplikasyonlarından biridir ve retinal vasküler yapıların tutulduğu özel bir anjiopatidir(1). Nonproliferatif diyabetik retinopati(NPDR) ve Proliferatif diyabetik retinopati(PDR) olmak üzere 2 evresi mevcuttur. Retinanın 6 tabakasını santral retinal arter besler(2).

Ultrason Elastografi doku elastisitesini ölçmek için geliştirilmiş yeni bir ultrason tekniğidir. Strain Elastografi(SE) ve Shear-Wave Elastografi(SWE) tipleri vardır. SWE ile objektif veriler elde etmek mümkündür ve daha güvenilirdir(3). Noninvaziv ve tekrarlanabilir olması tekniği daha değerli kılmaktadır.

Doppler; kan akım yönünü ve hızını belirleyen, vasküler yapılar ile ilgili bilgi veren bir ultrasonografi tekniğidir. Rezistif indeks(Ri) periferik vasküler direnci gösteren bir değerdir. Renkli Doppler incelemede piksistolik hızdan enddiastolik hızın çıkarılması ve piksistolik hıza bölünmesi ile elde edilir. Birimi yoktur ve doppler parametrelerinden etkilenmez(4). Biz bu çalışmamızda Diyabetik retinopatide optik sinir elastisitesini SWE ile değerlendirip santral retinal arter (SRA) Ri değerleri ile karşılaştırmayı amaçladık.

\section{Materyal ve Metod}

Çalışmamız 2021 yılında Şubat- Mart ayları arasında Radyoloji Anabilim Dalı'nda, Göz Hastalıkları Anabilim Dalı işbirliği ile gerçekleştirilen prospektif bir incelemedir. Çalışma için 15.02.2021 tarih 04 nolu oturum ve 36 nolu kararı ile Harran Üniversitesi Tıp Fakültesi Etik Kurulu'ndan onay alındı. Çalışmaya katılan tüm hastalardan aydınlatılmış onam alındı. Bu çalışmamızda 30 yaş üstü hastalar ve sağlıklı gönüllüler değerlendirildi. Hipertansiyon gibi başka sistemik hastalığı olanlar, oküler hastalığı olanlar çalışmaya dahil edilmedi. Göz Hastalıkları Anabilim Dalı Retina Polikliniği'ne başvuran tip 2 DM tanılı hastaların retinopati değerlendirmesi açısından fundus muayenesi yapıldı. Diyabetik retinopati sınıflaması ve klinik bulguları açısından değerlendirme yapıldı.
Bu muayenede diyabetik retinopatinin mevcut olduğu olgular ve retinopatinin evresi belirlendi. Retinopati tanısı konan ve retinopatisi olmayan hastalardan bölümümüze yönlendirilenler çalışmaya alındı.

Bu çalışmaya Diyabetik retinopatisi olan 31 hastanın 62 gözü dahil edildi. Kontrol grubunda 23 hastanın 46 gözü değerlendirildi. Tüm hastalara alanında uzmanlaşmış bir radyolog tarafından yarı karanlık Ultrasonografi odasında hasta supin pozisyonunda göz kapakları kapalı iken gri skala Ultrasonografi(US) ve elastografik inceleme yapıldı. Incelemeler SWE yazılımı bulunan Siemens ACUSON S3000 cihazının L9 lineer probu ile yapıldı. Her iki göz ve optik sinir ayrı ayrı değerlendirildi. Optik sinirin glob komşuluğundaki kesimlerinden SWE tekniği kullanılarak ardışık 3 ayrı ölçüm yapılıp ortalaması alındı ve $\mathrm{m} / \mathrm{sn}$ cinsinden değerler elde edildi. Daha sonra Renkli Doppler US inceleme ile santral retinal arter Ri değerleri ölçüldü.

\section{istatiksel Analiz}

İstatiksel veriler IBM SPSS V.20 istatistik programı ile elde edildi. Tek değişkenli analizlerde yüzde, ortalama ve standart sapma kullanıldı. Çok değişkenli analizlerde tek yönlü varyans analizi kullanıldı ve $p<0.05$ anlamlı kabul edildi.

\section{Bulgular}

Çalışmamızda sağlıklı gönüllüler, retinopatisiz DM, NPDR ve PDR olmak üzere 4 grup oluşturduk. Ayrıca sağlıklı gönüllüler ve retinopatisiz DM gruplarını retinopatisi olmayanlar; NPDR ve PDR gruplarını retinopatisi olanlar olarak sınıflayıp ayrı bir gruplama oluşturduk.

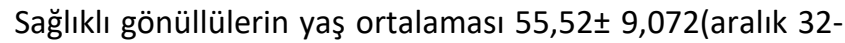
76 yaş), Retinopatisiz DM grubunda yaş ortalaması $56,22 \pm 10,01$ (aralık 45-79 yaş) idi. NPDR grubunda yaş ortalaması 56.98 11.18 (aralık 32-81 yaş), PDR grubunda yaş ortalaması $58.56 \pm 10.19$ (aralık $40-72$ yaş) idi. Dört grup arasında yaş açısından benzerlik bulundu.

Çalışmamızda 26 erkek ve 28 kadın dahil edildi. 108 göz değerlendirildi. Gruplar cinsiyet açısından benzer bulundu (Tablo 1).

Tablo 1. Çalışmaya dahil edilen hastaların demografik özellikleri

\begin{tabular}{ccccc}
\hline Değişkenler & Sağlıklı Gönüllüler & Retinopatisiz DM & NPDR & PDR \\
\hline Yaş & $55,57 \pm 8,98$ & $56 \pm 10,67$ & $56,98 \pm 11,18$ & $58,56 \pm 10,19$ \\
\hline Cinsiyet & & & & \\
Kadın & 28 & 6 & 18 & 4 \\
Erkek & 18 & 3 & 26 & 5 \\
\hline
\end{tabular}

Dört grupta optik sinir elastisitesi SWE ile değerlendirildi ve dört grup arasında anlamlı farklılık saptandı $(p<0,05)$. Ancak öngördüğümüz gibi doğrusal bir artış izlenmedi. Retinopatisi olan hastalar ile retinopatisi olmayanlar arasında yaptığımız değerlendirmede retinopatisi olan hastalarda SWE değerleri anlamlı olarak yüksek saptandı(Tablo 2).
Santral retinal arter Ri değerleri retinopatisi olanlarda olmayanlara göre anlamlı olarak yüksek izlendi $(p<0,05)$ (Tablo 2$)$. Retinopatisi olmayanlarda Ri değerleri $0,57 \pm 0,88$ ve retinopatisi olanlar için ise $0,67 \pm 0,53$ olarak ölçüldü. Santral retinal arter Ri değerlerini 4 grupta (sağlıklı gönüllüler, retinopatisiz DM, NPDR ve PDR) karşılaştırdığımızda anlamlı farklılık izlenmedi (Tablo 3). 
Tablo 2. Retinopatisi olan ve olmayan gruplarda SW ve Ri değerleri

\begin{tabular}{ccc}
\hline & $\begin{array}{c}\text { Retinopatisi } \\
\text { olmayanlar } \\
\text { (ortalama } \pm \text { SD) }\end{array}$ & $\begin{array}{c}\text { Retinopatisi olanlar } \\
\text { (ortalama } \pm \text { SD) }\end{array}$ \\
\hline SW Değeri & $1,61 \pm 0,48$ & $2,01 \pm 0,45$ \\
Ri & $0,57 \pm 0,88$ & $0,67 \pm 0,53$ \\
\hline
\end{tabular}

Tablo 3. 4 grupta SW ve Ri değerleri

\begin{tabular}{|c|c|c|c|c|c|}
\hline & $\begin{array}{l}\text { Sağlıklı Gö- } \\
\text { nüllüler } \\
\text { (Ort. } \pm S D)\end{array}$ & $\begin{array}{c}\text { Retinopa- } \\
\text { tisiz DM }\end{array}$ & NPDR & PDR & $p$ \\
\hline $\mathbf{R i}$ & $0,57 \pm 0,14$ & $0,58 \pm 0,95$ & $0,66 \pm 0,05$ & $0,71 \pm 0,03$ & 0.490 \\
\hline SW & $1,61 \pm 0,46$ & $1,57 \pm 0,58$ & $2,04 \pm 0,65$ & $1,88 \pm 0,71$ & 0.001 \\
\hline
\end{tabular}

\section{Tartışma}

Diyabetik retinopati, Diyabetes mellitusun en önemli komplikasyonlarından biridir. Önlenebilir ve/veya tedavi edilebilir körlüğün en önemli nedenidir.

Literatürde diyabetik retinopatili hastalarda optik sinir elastografisini değerlendiren herhangi bir çalışmaya rastlanmadı. Ancak başka patolojilerde optik sinir elastografisi ile ilgili çeşitli çalışmalar mevcuttur.

Dikici ve arkadaşlarının yaptığı bir çalışmada glokom hastaları ve kontrol grubu Shear-Wave Elastografi ile değerlendirildi. İki grup arasında elastografi değerleri anlamlı farklılık gösterdi(5).

Asal ve arkadaşları preeklampsisi olan ve olmayan gebelerin optik sinir elastisitesini Shear-Wave Elastografi ile değerlendirdi ve sağlıklı gönüllüler ile kıyasladı. Gruplar arasında anlamlı farklılık bulundu(6).

Son yıllarda dokuların elastisitesi ile histolojik özellikleri arasında yakın ilişki olduğunu gösteren çalışmalar dikkat çekmektedir(7). Diyabetik retinopatide nöroretinada hücresel değişiklikler meydana gelmektedir. Retinada ve devamı olan optik sinirde müller hücrelerinde aktivasyon(8) ile astrosit sayı ve aktivasyonunda azalma(9) çeşitli çalışmalarla gösterilmiştir. Ayrıca yeni gelişen damarların etrafında aktif mikrogliya hücrelerinin olduğu gösterilmiştir(10). Yine diyabetik retinopatide retinal ganglion hücre hasarı olduğu ve bu hücrelerin sayısının azaldığı tespit edilmiştir. Tüm bu değişikliklerin optik sinirde elastisitede değişikliğe yol açtığı düşünülebilir.

$\mathrm{Ri}$, vasküler direncin bir göstergesidir ve diabetik retinopatideki orbital dolaşım bozukluğu ile ilgili bilgi verebilir. DR'de oluşan vasküler endotelyal hasar kapiler sızıntıya ve sonrasında retinal iskemiye yol açar. Buna sekonder devreye giren otoregülasyon mekanizmaları hiperperfüzyonu uyararak endotel hasarına katkıda bulunur(1). Diabetes Mellitus'ta retinopati ile oküler dolaşım bozukluğu arasında ilişki olduğunu gösteren çalışmalar mevcuttur.

Goebel ve arkadaşları diabetik hastalarda santral retinal arterde kan akış hızının azaldığını ve retinopatinin ilerlemesiyle kan akımındaki azalmanın belirginleştiğini tespit etti(11).
Manila Khatri ve arkadaşları Diyabetik retinopatide santral retinal arter Ri değerlerini ölçtü. Bizim çalışmamızda olduğu gibi 4 grup oluşturdu. Bu çalışmada gruplar arasında santral retinal arter Ri değerleri açısından anlamlı farklılık saptandı ve SRA Ri değerlerindeki artış, Optik Koherens Tomografi tabanlı retinal yapısal değişikliklerle ilişkili bulundu (12). Tüm bu çalışmalar vasküler değişikliklerin ve artan retinal kan akımının DR etyopatogenezinde rol aldığını düşündürmektedir. Başka bir çalışmada orbital rezistif indeksin DR'nin erken tanı ve takibinde yararlı bir belirleyici olduğu bulundu(13). Ayrıca Koç ve arkadaşları akut santral seröz korioretinopatili hastalarda kontrol grubuna oranla oküler vasküler direnç parametrelerinde anlamlı artış saptadı (14).

Çalışmamızda öngörümüzden farklı olarak sağlıklı gönüllülerde elastografi değerlerimiz retinopatisiz DM grubuna göre yüksek çıktı. Aynı şekilde NPDR grubunda PDR grubuna göre daha yüksek değerler ölçtük. Ancak retinopatiyi baz alarak yaptığımız değerlendirmede retinopati olan grupta optik sinir elastisitesini ve santral retinal arter Ri değerlerini retinopati olmayan gruba göre anlamlı olarak daha yüksek ölçtük. Bu veriler diyabetik retinopatinin erken tanı ve takibinde kullanılabilecek önemli parametreler olabilir ve umut vericidir. Çalışmamızdan elde ettiğimiz verilere göre diabetik retinopatide optik sinir sertlik derecesi anlamlı olarak artış göstermektedir ve vasküler direnç artmaktadır. Optik sinir elastisitesindeki artış ve vasküler direnç artışı arasında bir nedensonuç ilişkisi kurulabilir.

Çalışmamızın çeşitli limitasyonları bulunmaktadır. Tip 2 DM hastaları ile çalıştığımız için 30 yaş altı hastalarımız yoktu. Ayrıca DM hastalarının çoğuna Hipertansiyon, Kronik Böbrek Yetmezliği gibi ek hastalıklar eşlik ettiğinden az sayıda izole DM hastasını çalışmamıza dahil edebildik.

\section{Sonuç}

Sonuç olarak; NPDR ve PDR' nin etyopatogenezi hala tartışmalı olmakla birlikte, literatürde çeşitli etyolojik hipotezler bulunmaktadır. Vasküler dolaşımda meydana gelen değişikliklerin de olası sebeplerden biri olduğu düşünülmektedir. Bizim elde ettiğimiz sonuçlar da bu tezi desteklemektedir. Bize ait çalışmada diyabetik retinopatide vasküler direnç parametresinde Ri izlenen anlamlı artışın, optik sinir sertliği ile ilişkili olabileceği de öngörülmektedir.

RDUS, NPDR ve PDR'de oküler hemodinamik değişikliklerin tespitinde başvurulabilecek önemli bir radyolojik görüntüleme metodu olup tanıda önemli ve etkin bir rol oynayabileceğini düşünüyoruz. Aynı zamanda Shear Wave Elastagrafi tekiniği de hızlı, güvenilir ve non invaziv bir görüntüleme tekniği olarak diyabetik retinopati gibi oküler hastalıkların erken teşhisinde önemli rol oynayabilir. 
Etik onam: Çalışma öncesi Harran Üniversitesi Tıp Fakültesi Girişimsel Olmayan Klinik Araştırmalar Etik Kurulundan onay alındı. (Onam no: 04/36, Onam tarihi: 15.02.2021).

\author{
Yazar Katkıları: \\ Konsept: C.Ç \\ Literatür Tarama: A.K \\ Tasarım: Ş.A. \\ Veri toplama: C.Ç. \\ Analiz ve yorum: A.D. \\ Makale yazımı: C.Ç. \\ Eleştirel incelenmesi: D.S.D. \\ Çıkar Çatışması: YOK \\ Finansal Destek: YOK
}

\section{Kaynaklar}

1. Inan S. Diabetic Retinopathy and Etiopathogenesis. Kocatepe Medical Journal. 2014; 15(2): 207-17.

2. Blodi FC. Eugene Wolff's anatomy of the eye and orbit. Arch Ophthalmol. 1977; 95:1284.

3. Taş $S$, Onur MR, Yılmaz $S$, Soylu AR, Korkusuz F. ShearWaveElastography Is a Reliableand Repeatable Method for Measuring the Elastic Modulus of the Rectus Femoris Muscle and Patellar Tendon. J Ultrasound Med. 2017 Mar; 36(3):565-70.

4. Sancak IT. Temel Radyoloji. Güneş Tıp Kitapevleri. 2015; 6186.

5. Dikici AS, Mihmanli I, Kilic F, Ozkok A, Kuyumcu G, Sultan P et al. In Vivo Evaluation of the Biomechanical Properties of Optic Nerve and Peripapillary Structures by Ultrasonic Shear Wave Elastography in Glaucoma. Iran J Radiol. 2016; 13(2):e36849.

6. Asal N, Sayan CD, Gökçınar NB, Şahan MH, Doğan A, İnal M. Evaluation of the optic nerve using strain and shear-wave elastography in pre-eclampsia. Clinical Radiology. 2019; 74(10): 813.e1-813.e9.

7. Thitaikumar A, Ophir J. Effect of lesion boundary conditions on axial strain elastograms: a parametric study. Ultrasound Med Biol 2007; 33:1463-7.

8. He $C$, Sun $Y$, Ren $X$, Lin $Q$, Hu X, Huang $X$ et al. Angiogenesis mediated by toll-like receptor 4 in ischemic neural tissue, Arterioscler Thromb Vasc Biol. 2013; 33:330-8.

9. Rungger-Brandle $E$, Dosso AA, Leuenberger PM. Glial reactivity, an early feature of diabetic retinopathy, Invest Ophthalmol Vis Sci. 2000; 41:1971-80.

10. Li L, Eter N, Heiduschka P. The microglia in healthy and diseased retina. Experimental Eye Research, 2015; 136:11630.

11. Goebel W, Lieb WE, Ho A, Sergott RC, Farhoumand R, Grehn F. Color Doppler imaging: a new technique to assess orbital blood flow in patients with diabetic retinopathy. Invest Ophthalmol Vis Sci. 1995; 36:864-870.

12. Khatri M, Saxena $S$, Kumar M, Chabbra AK, Bhasker SK, AKduman $\mathrm{El}$ et al. Resistive index of central retinal artery is a bioimaging biomarker for severity of diabetic retinopathy. International Journal of Retina and Vitreous. 2019; 5:38.

13. Basturk T, Albayrak R, Ulas T, Akcay M, Unsal A, Toksoy M, Koc Y. Evaluation of resistive index by color Doppler imaging of orbital arteries in type II diabetes mellitus patients with microalbuminuria. Ren Fail. 2012; 34:708-712.

14. Koc M, Deniz N, Serhatlıoğlu S. Akut Santral Seröz Korioretinopatide Renkli Doppler Ultrasonografi ile Orbital Akım
Parametrelerinin Değerlendirilmesi. Fırat Tıp Dergisi 2008; 13(2): 120-122. 